Int. J. Dev. Biol. 60: 111-117 (2016)

doi: $10.1387 / \mathrm{ijdb} .130253 \mathrm{sg}$

\title{
UV induced foot duplication in regenerating hydra is mediated by metalloproteinases and modulation of the Wnt pathway
}

\author{
LAKSHMI-SUREKHA KRISHNAPATI ${ }^{1}$, ROHINI LONDHE ${ }^{1}$, VAISHALI DEOLI ${ }^{1}$, APURVA BARVE ${ }^{\#, 1}$, \\ SAROJ GHASKADBI ${ }^{2}$ and SURENDRA GHASKADBI*,1 \\ ${ }^{1}$ Developmental Biology Group, MACS-Agharkar Research Institute and \\ ${ }^{2}$ Department of Zoology, Savitribai Phule Pune University, Pune, India
}

\begin{abstract}
We have shown earlier that irradiation with UV induces duplication of foot in regenerating middle pieces of hydra. The present study was undertaken to elucidate the underlying mechanism(s) leading to this curious phenomenon. UV irradiation induced duplicated foot in about $30 \%$ of regenerating middle pieces. Metalloproteinases are important in foot formation, while Wnt pathway genes are important in head formation in hydra. The effect of UV irradiation on expression of these genes was studied by in situ hybridization and q-PCR. In whole polyps and middle pieces, UV irradiation led to up-regulation of HMP2 and HMMP, the two metalloproteinases involved in foot formation in hydra. HMP2 expression was significantly increased starting from 30 min post exposure to UV at $254 \mathrm{~nm}\left(500 \mathrm{~J} / \mathrm{m}^{2}\right)$, while HMMP showed significant up-regulation $6 \mathrm{~h}$ post UV exposure onwards. In middle pieces, increased expression of both metalloproteinases was observed only at $48 \mathrm{~h}$. In whole polyps as well as in middle pieces, expression of Wnt3 and $\beta$-catenin was detected within $30 \mathrm{~min}$ of UV exposure and was accompanied by up-regulation of GSK3 $\beta, D K K 3$ and $D K K 1 / 2 / 4$, inhibitors of the Wnt pathway. These conditions likely lead to inactivation of Wnt signaling. We therefore conclude that duplication of foot due to UV irradiation in regenerating middle pieces of hydra is a combined effect of up-regulation of metalloproteinases and inactivation of the Wnt pathway. Our results suggest that UV irradiation can be employed as a tool to understand patterning mechanisms during foot formation in hydra.
\end{abstract}

KEY WORDS: Hydra, metalloproteinase, pattern formation, UV-induced foot duplication, Wnt signaling

\section{Introduction}

Hydra, a representative of phylum Cnidaria, has been a popular model to study various developmental processes owing to its structural simplicity and remarkable capacity for regeneration (Ghaskadbi et al., 2005). Hydra shows a simple body plan with oral/aboral axis, the formation of which depends on the concentration of several morphogenetic gradients along the axis. Various exogenous agents such as UV, lithium chloride, alsterpaullone, etc. have been used as tools to understand the molecular mechanisms responsible for pattern formation in hydra. Previous studies from our laboratory have shown that UV irradiation induces duplication of foot in about one third of regenerating middle pieces of trisected hydra and increases budding in intact hydra (Ghaskadbi et al., 2005). Based on this work, we hypothesized that UV-induced formation of duplicated foot in regenerating hydra could involve up-regulation of matrix metalloproteinases (MMPs) and/or inactivation of Wnt pathway genes.

Metalloproteinases are responsible for degradation of macromolecules such as collagen, gelatine and other glycoproteins (reviewed in Birkedal-Hansen et al., 1993 and Page-McCaw et al., 2007). Degradation of these components initiates ECM-cell interactions which are essential for various processes during

Abbreviations used in this paper: UV, ultra violet.

*Address correspondence to: Surendra Ghaskadbi. Coordinator, Developmental Biology Group, MACS-Agharkar Research Institute, G.G. Agarkar Road, Pune-411 004, India. Tel: +91-20-2532-5063. Fax: +91-20-2565-1542. E-mail: ghaskadbi@gmail.com

\#Present address: Indian Institute of Science Education and Research, Pune -411 008, India 


\section{L.S. Krishnapati et al.}

embryonic development and morphogenesis (Sarras et al., 1993, Zhang and Sarras, 1994). Earlier studies have shown that ECMcell interactions are crucial for certain developmental processes in hydra (Sarras et al.,1994; Zhang and Sarras, 1994). Three metalloproteinases, HMP2, an Astacin metalloproteinase (Yan et al., 2000), HMMP, a matrix metalloproteinase (Leontovich et al., 2000) and MMP-A3 another matrix metalloproteinase (Münder et al., 2010; Aufschnaiter et al., 2011) have been characterized from hydra and are shown to be involved in foot morphogenesis, regeneration and in separation of buds, respectively. Further, UV irradiation has been shown to induce MMPs in human skin and canine cornea (Brenneisen et al., 2002, Brennan et al., 2003, Chandler et al., 2008, Amano, 2009).

Numerous developmental processes including cell proliferation, migration and differentiation, fate specification, dorso-ventral patterning and maintenance of cell polarity are mediated by Wnt family of glycoproteins (Komiya and Habas, 2008). The canonical Wnt pathway involves inactivation of GSK3 $\beta$ followed by $\beta$-catenin-Tcf coupled activation of transcription of genes that play critical role in developmental processes (Broun et al., 2005, Eastman et al., 1999, Molenaar et al., 1999). In hydra, Wnt3 is involved in setting up the Organizer and the genes involved in Wnt pathway are strongly expressed in the hypostome region (Hobmayer et al., 2000; Bode 2003, Broun et al., 2005). In the present study, we show that exposure to UV up-regulates the metalloproteinases, HMP2 and HMMP and inactivates overall Wnt pathway by activating Wnt inhibitors in regenerating middle pieces of hydra, demonstrating that both these mechanisms contribute to formation of a duplicated foot.

\section{Results}

\section{Duplication of foot in UVirradiated regenerating middle pieces}

Our previous work has shown that exposure to UVC induces formation of duplicated foot in 33\% of regenerating middle pieces of hydra (Ghaskadbi et al., 2005). In the present study, we have treated whole polyps and middle pieces of Hydra vulgaris Ind-Pune with UVC and allowed these to recover in hydra medium for 4-5 days. Irradiated whole polyps recovered in medium for $24 \mathrm{~h}$ showed reduced body length with shortened tentacles or no tentacles with swollen head/hypostome in $90 \%$ animals. Foot specific staining was performed on regenerated middle pieces (Fig. 1A) which showed duplication of foot in about $30 \%$ of irradiated regenerating middle pieces (Fig. 1 B,C). UV irradiated middle pieces recovered in medium did not show significant difference in head morphology (Fig. $1 \mathrm{C} \mathrm{g-h).} \mathrm{These} \mathrm{data} \mathrm{confirm} \mathrm{our} \mathrm{earlier} \mathrm{observation} \mathrm{(Ghaskadbi} \mathrm{et}$ al., 2005). It may be mentioned here that the species used in the earlier study, Pelmatohydra oligactis is identical to Hydra vulgaris used in the present study. The reason behind the difference in name is that the species was earlier misnamed as Pelmatohydra oligactis and has since been taxonomically restudied and identified recently by us as Hydra vulgaris Ind Pune (Reddy et al., 2011).

\section{Induction of metalloproteinases by UV irradiation}

Whole mount in situ hybridization and q-PCRs were performed to compare the localization and expression levels of metalloproteinases in control and UV treated polyps. In situ hybridization showed up-regulation of metalloproteinases in UV treated polyps. Expression pattern of HMP2 in control hydra was comparable to the reported pattern in Hydra vulgaris (Yan et al., 2000), which showed localization in the basal region and extended along the lower body column (Fig. $2 \mathrm{Aa}$ ). UV exposure not only increased the expression of HMP2 but also enhanced its domain of expression except in the hypostome region (Fig. $2 \mathrm{Ab}$ ).

In order to confirm the up-regulation of metalloproteinases by UV irradiation, q-PCRs were carried out for control- and UVtreated polyps and middle pieces. UV irradiation of whole polyps and middle pieces resulted in increased expression of both HMP2 and $H M M P$ (Fig. 4). Up-regulation of HMP2 was observed as early as 30 min post-treatment and continued to increase up to $24 \mathrm{~h}$ as compared to control. Significant up-regulation of $H M M P$ was seen after 6 and $24 \mathrm{~h}$ (Fig. 4A). Unlike in whole hydra, UV irradiation resulted in significant up-regulation of HMP2 and HMMP at $48 \mathrm{~h}$ in middle pieces (Fig. 4B).

\section{Effect of UV irradiation on Wnt signaling}

Expression of Wnt3, $\beta$-catenin, DKK3, DKK1/2/4 and GSK3 $\beta$ was studied by in situ hybridization and q-PCR. Whole polyps and middle pieces exposed to UVC at $500 \mathrm{~J} / \mathrm{m}^{2}$ and recovered in hydra

A

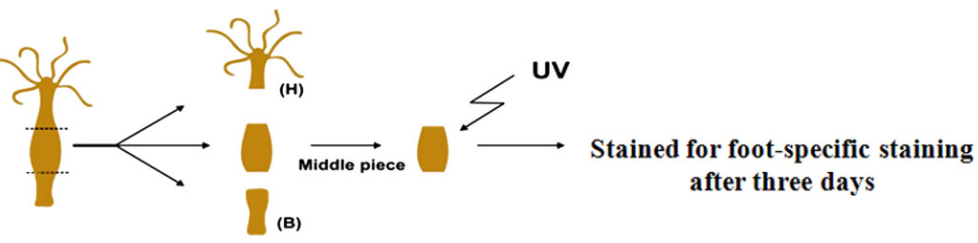

B

\begin{tabular}{|c|c|c|}
\hline $\begin{array}{c}\text { No. of UV treated } \\
\text { middle pieces }\end{array}$ & $\begin{array}{c}\text { No. of Hydra with } \\
\text { ectopic foot }\end{array}$ & Percentage \\
\hline 187 & 57 & $30.48 \%$ \\
\hline
\end{tabular}

C
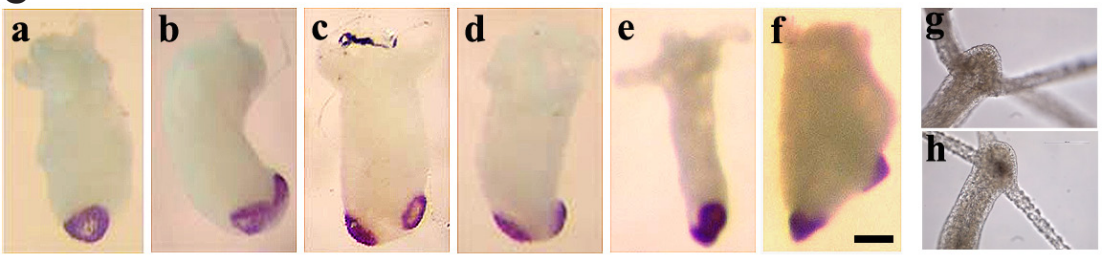

Fig. 1. UV irradiation-induced duplication of foot in regenerating middle pieces of hydra. Middle pieces of hydra were irradiated with $500 \mathrm{~J} / \mathrm{m}^{2}$ UV at $254 \mathrm{~nm}$ and regeneration was monitored over a period of 4-5 days. (A) Schematic representation of trisection and irradiation of middle piece followed by foot-specific staining in the regenerates. (B) Quantification of UV irradiation-induced duplicated foot formation in the middle pieces. (C) UV irradiation-induced duplication of foot (b-f) as opposed to a single foot in unirradiated, control middle piece (a) was detected by foot specific staining. UV irradiated middle pieces recovered in medium (h) did not show significant difference in head morphology when compared to control (g). Scale bar, $200 \mu \mathrm{m}$. 
A $24 \mathrm{~h}$

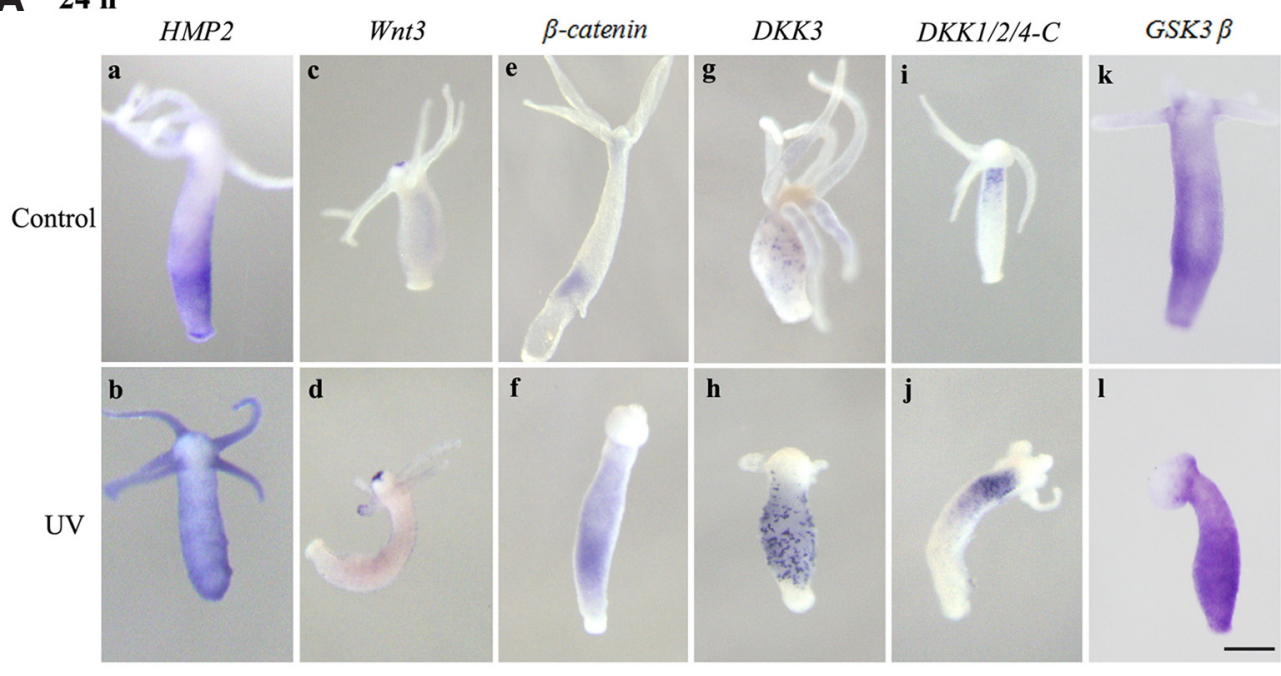

B $0.5 \mathrm{~h}$

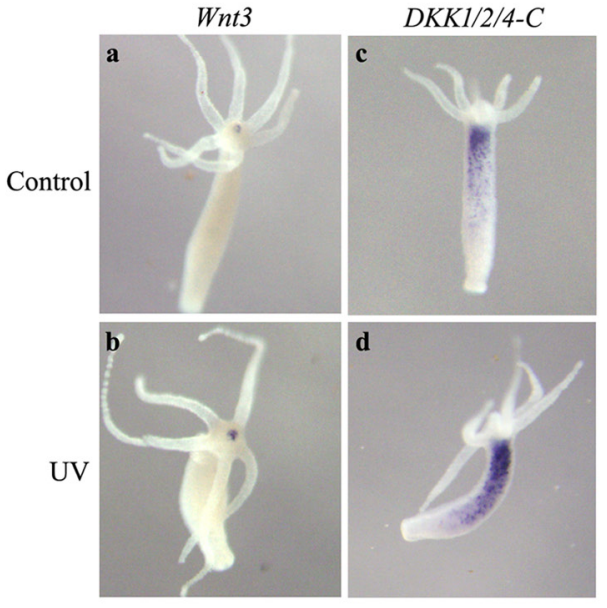

C $6 \mathrm{~h}$
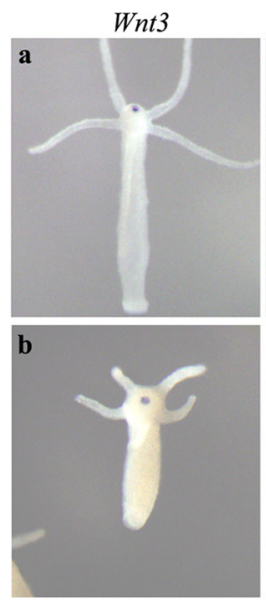

$D K K 1 / 2 / 4-C$
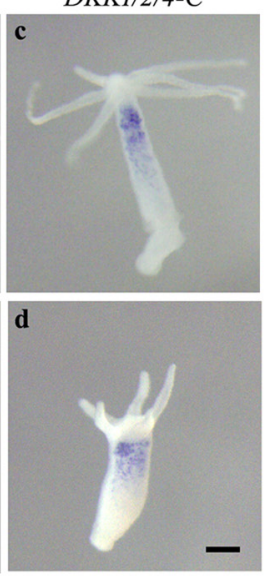

Fig. 2. Localization of $H M P 2, W n t 3, \beta$ catenin, $D K K 3, D K K 1 / 2 / 4-C$ and GSK3 $\beta$ by whole mount in situ hybridization DIG labeled antisense probes were used for the detection of transcripts. (A) Enhanced expression of HMP2 (b), Wnt3 (d), $\beta$-catenin (f), DKK3 (h), DKK1/2/4-C (j) and GSK3 $\beta$ (I) was observed in UV treated whole hydra post 24 h recovery in hydra medium as compared to controls $(\mathbf{a}, \mathbf{c}, \mathbf{e}, \mathbf{g}, \mathbf{i}$, k), respectively. Expression of Wnt3 and DKK1/2/4-C in irradiated polyps after 0.5(B) and $6 \mathrm{~h}(\mathbf{C})$ recovery. Strong expression of Wnt 3 and DKK $1 / 2 / 4-C$ was seen in irradiated polyps after $0.5 \mathrm{~h}(B, b, d)$ and $6 h(C, b, d)$ recovery. Scale bar, $200 \mu \mathrm{m}$. medium for 0.5, 6, 24 and $48 \mathrm{~h}$ were used for in situ hybridization. In situ hybridization in UV irradiated whole polyps recovered after $24 \mathrm{~h}$ showed up-regulation of Wnt3, $\beta$-catenin, DKK3, DKK1/2/4 and GSK3 $\beta$ (Fig. 2A). Enhanced expression of Wnt3and $\beta$-catenin post UV irradiation suggests possible activation of Wnt pathway. Though the expression of Wnt3 was restricted to the hypostome, its expression was more intense in UV treated polyps (Fig 2A, d) as compared to controls (Fig 2A, c). Similarly, $\beta$-catenin expression was enhanced in the body column with strongest signal in the budding region in UV treated polyps as compared to controls (Fig $2 \mathrm{~A} e, \mathrm{f})$. Simultaneously, expression of inhibitors of Wnt pathway, $D K K 3, D K K 1 / 2 / 4-C$ and GSK3 $\beta$ was also enhanced as a result of UV irradiation. In control hydra, expression of $D K K 3$ was seen in the differentiating nematocytes of gastric region (Fig. 2A, g) and $D K K 1 / 2 / 4-C$ in gland cells in a graded expression pattern with high expression from sub-tentacle region (Fig. 2A, i) as previously reported (Fedders et al., 2004; Augustin et al., 2006). Upon irradiating with UV, expression of $D K K 3$ (Fig. $2 \mathrm{~A}$, h) and $D K K 1 / 2 / 4-C$ (Fig. $2 \mathrm{~A}$, j) was increased as compared to the control polyps (Fig. 2A $\mathrm{g}, \mathrm{i})$. Similarly, in control hydra, expression of $G S K 3 \beta$ was seen all over the body and at the tentacle boundaries (Fig. 2Ak) whereas in
UV treated hydra (Fig. 2A, I) GSK3 $\beta$ expression was more intense than control hydra (Fig.2A, k).

In situ hybridization in whole polyps recovered after 0.5 and 6 $\mathrm{h}$ also showed up-regulation of Wnt3 and DKK1/2/4-C (Fig. 2B, C). In middle pieces, expression of Wnt3 was seen in regenerating heads in controls (Fig. 3A, a; 3B, a) while its expression was enhanced in UV treated middle pieces after 0.5 (Fig. $3 A$, b) and $6 \mathrm{~h}$ (Fig. 3B, b). However, expression of Wnt3 after 24 and $48 \mathrm{~h}$ recovery did not show specific pattern in UV treated middle pieces (Fig. 3C, b and 3D, b), while DKK1/2/4-Cexpression was increased in regenerating heads from early recovery and continued till $48 \mathrm{~h}$ (Fig. 3C, d; 3D, d).

Analysis by q-PCR also showed up-regulation of Wnt3 immediately after UV irradiation till $24 \mathrm{~h}$, with a maximum expression at $6 \mathrm{~h}$ (Fig. 5A). Up-regulation of $\beta$-catenin, DKK3 and GSK3 $\beta$ was also observed in UV irradiated hydra, confirming the in situ hybridization results (Fig. 5A). Comparison of expression patterns of Wnt3, DKK3 and GSK3 $\beta$ clearly shows that DKK3 and GSK3 $\beta$ are up-regulated when $W n t 3$ becomes active and down-regulated when Wnt signaling decreases (Fig. 5B), which points towards overall inactivation of Wnt pathway. Middle pieces also showed 
up-regulation of DKK3 and GSK3 $\beta$ along with Wnt and $\beta$-catenin (Fig. 6) confirming the overall down-regulation of Wnt pathway.

\section{Discussion}

The genesis of this study is in the curious observation that UV irradiation induces duplication of foot in regenerating middle pieces of hydra (Ghaskadbi et al., 2005). UV irradiation at the dose of 500 $\mathrm{J} / \mathrm{m}^{2}$ was found to reprogram patterning processes in about a third of the middle pieces. When a hydra is cut into pieces, each piece, except for the extreme oral/aboral tissues, regenerates into small adult polyp maintaining the head-base polarity (Bode, 2003). This maintenance of axial polarity is due to the presence of different morphogen gradients (Bode, 2009). We hypothesized that UV irradiation could affect these morphogen gradients that specify the oral/aboral axis, leading to duplication of foot in regenerates. One of the signaling pathways critical for head specification and formation in hydra is the Wnt pathway (Bode, 2009). Therefore we examined the effect of UV irradiation on Wnt pathway genes in intact and regenerating pieces of hydra. The other possibility
A

$0.5 \mathrm{~h}$

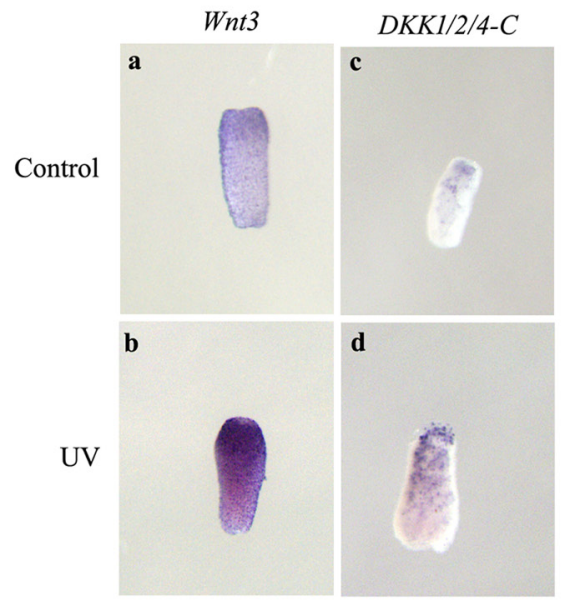

C $24 \mathrm{~h}$

Wnt3
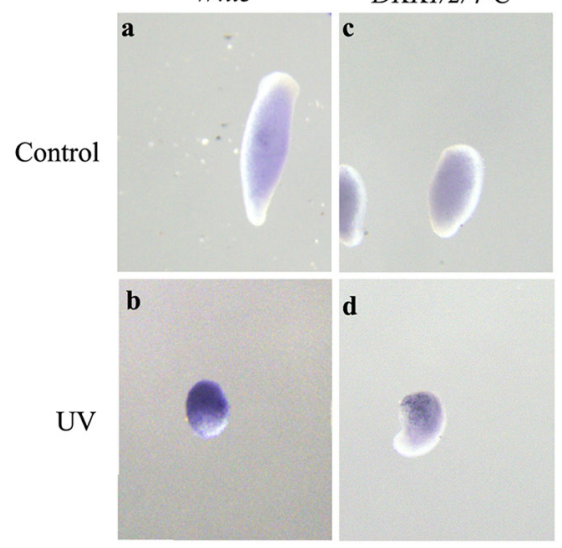

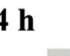

B $6 \mathrm{~h}$

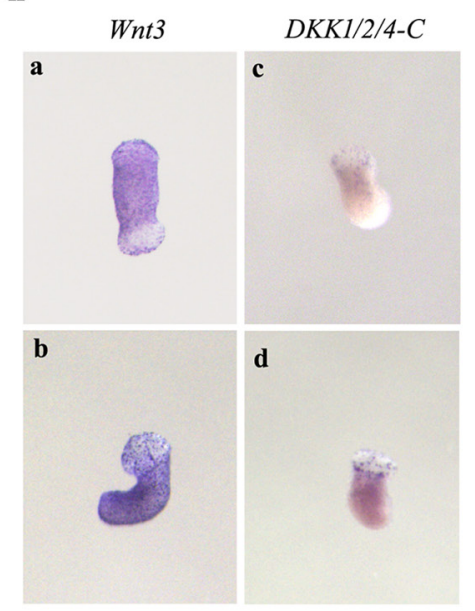

D $48 \mathrm{~h}$

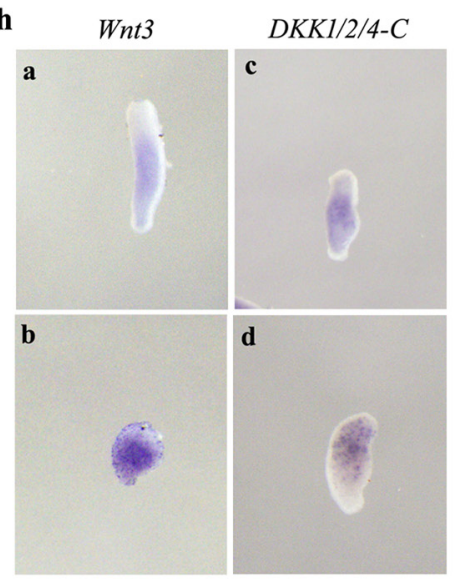

Fig. 3. Localization of Wnt3 and $D K K 1 / 2 / 4-C$ in middle pieces by whole mount in situ hybridization. Wnt3 (Ab, Bb) and DKK1/2/4-C (Ad, Bd) expression is up-regulated after early recovery time points, 0.5 and $6 \mathrm{~h}$ post UV treatment. DKK $1 / 2 / 4-\mathrm{C}$ expression is continued in regenerating pieces after $24(\mathbf{C d})$ and $48 \mathrm{~h}$ recovery $(\mathbf{D d})$ while no specific pattern was observed for Wnt3 expression. we considered and experimentally tested was the possible effects of UV radiation on the expression of metalloproteinase genes. As mentioned earlier, two metalloproteinases in hydra, HMP2, an Astacin metalloproteinase and HMMP, a matrix metalloproteinase participate in foot formation (Leontovich et al., 2000, Yan et al., 2000). It is known from previous studies that UV radiation leads to up-regulation of MMPs in human skin (Brenneisen et al., 2002, Brennan et al., 2003; Amano, 2009). Also, it has been demonstrated that Snail family transcription factors induced by UV via mitogen-activated protein kinase (MAPK) pathway can modulate MMP induction (Chandler et al., 2008), while in keratinocytes UV irradiation produces a variety of cytokines that can induce metalloproteinases in human skin (Dong et al., 2008).

Reports from earlier studies have shown that DNA damaging agents such as aluminium trigger morphological and behavioural changes, including DNA damage, in green and brown hydra (Kovačević et al., 2007). Previous results from our laboratory have shown that $X P F$, a UV responsive gene, is expressed in higher amounts in the ectoderm than in endoderm. Further, it is expressed in significantly high levels in the interstitial stem cells that are truly multipotent (Barve et al., 2013). Efforts are currently on to find out if XPF indeed participates in the nucleotide excision repair in hydra. In the present work, we have confirmed, using a much larger sample size, that irradiation of middle pieces with UV leads to formation of duplicated foot in about one third of the cases. Our quantitative PCR data show that UV irradiation leads to up-regulation of $H M M P$ and $H M P 2$, which may have been primarily responsible for the formation of duplicated foot. Wnt is responsible for setting up the head organizer in hydra (Hobmeyer et al., 2000), and inhibits the formation of a foot in the near vicinity. In the present study, we believe that up-regulation of Wnt inhibitors, DKK3, DKK1/2/4Cand GSK3 $\beta$ simultaneously with Wntmay have contributed to the formation of duplicated foot. Up-regulation of $D K K 1$, a homolog of $D K K 3$, by UV irradiation has been reported (Grotewold and Rüther, 2002; Shou et al., 2002). Further, reversal of Wnt induced morphological alterations in fibroblasts due to simultaneous expression of $D K K 1$ and $W n t-2$ has been demonstrated (Fedi et al., 1999). Our results point towards a similar mechanism in which simultaneous up-regulation of Wnt and its inhibitors, DKK3 and DKK1/2/4-C may have resulted in overall inactivation of Wnt pathway. Thus, formation of duplicated foot by UV irradiation is probably due to induction of HMP2 and $H M M P$ in the body column along with overall inhibition of Wnt pathway. Another possibility for duplicated foot formation could be change in head- and foot-activating gradients by activated Wnt in such a way that it inhibits foot inhibition resulting in the formation of duplicated foot. At present, we do not have any data suggesting a connection between DNA damaging ability of UV radiation and its effects on patterning during regeneration in hydra. 


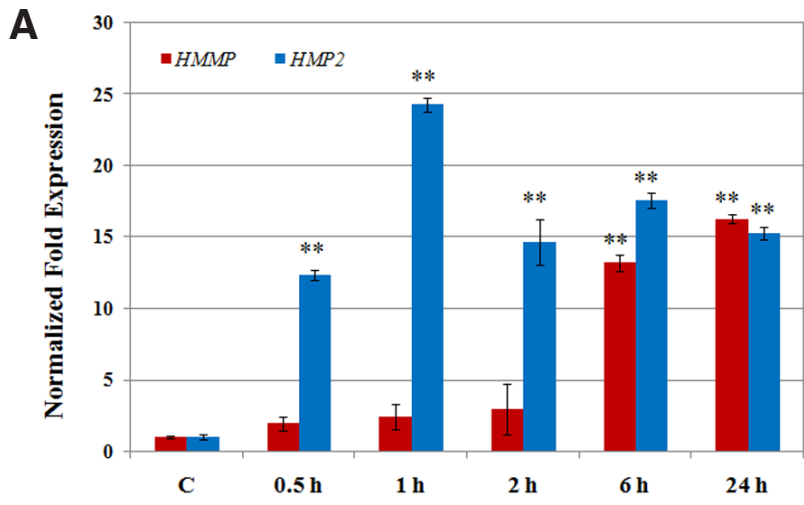

A
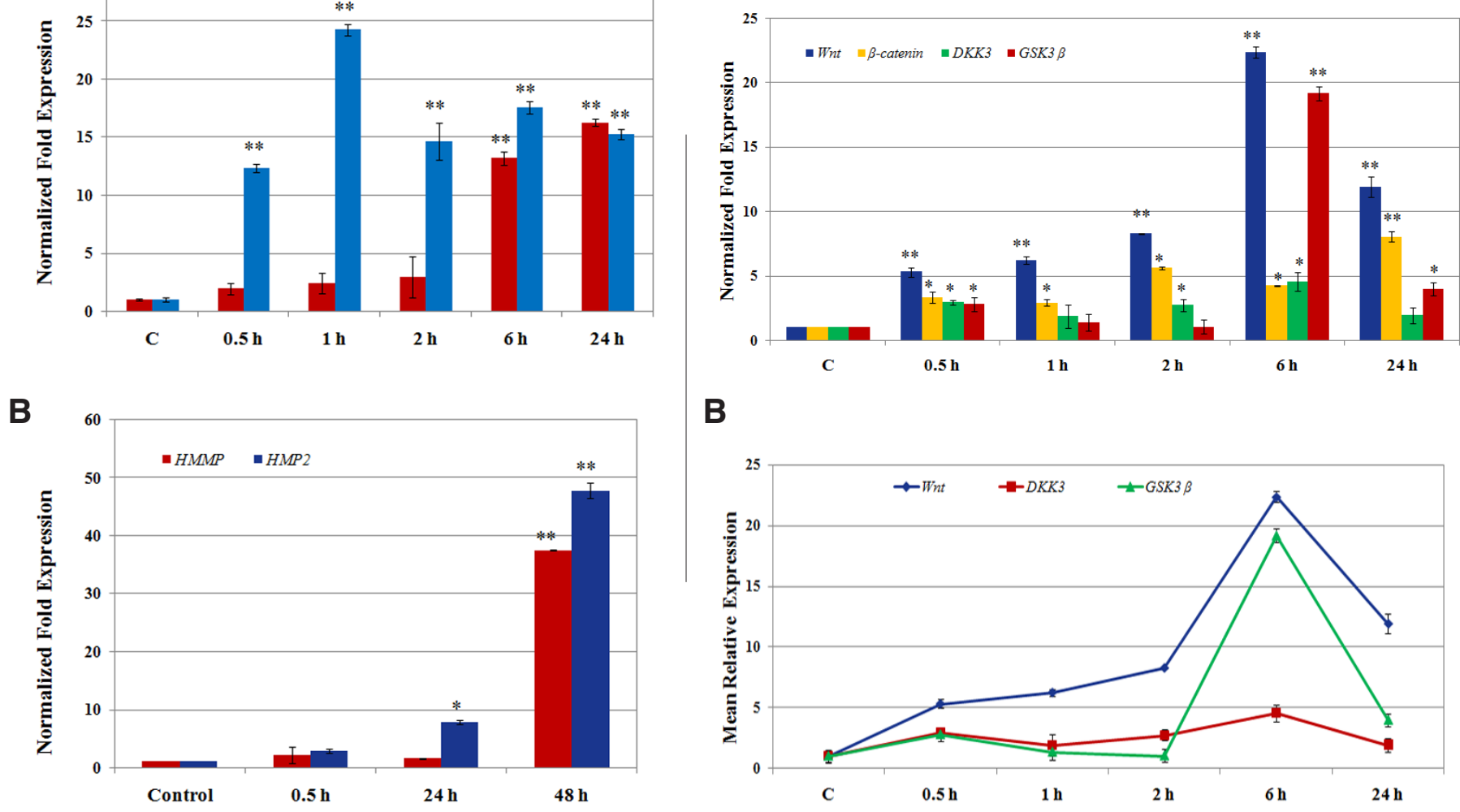

B

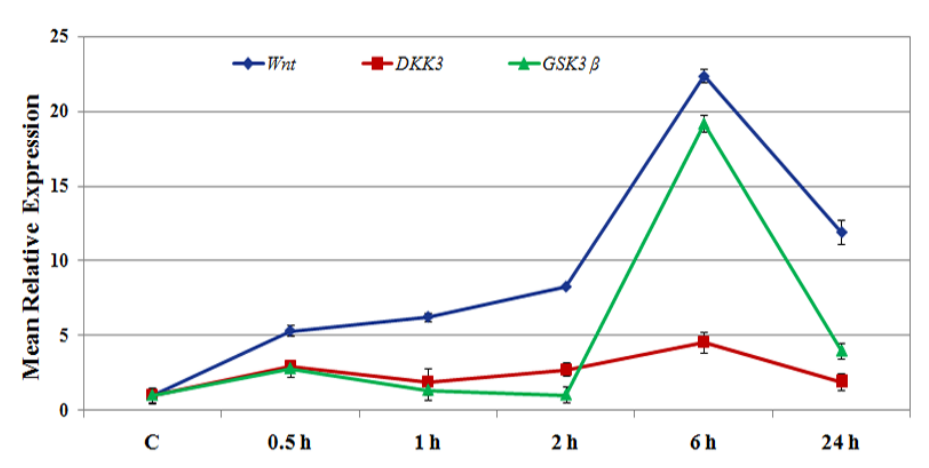

Fig. 4 (Left). Up-regulation of metalloproteinases with UV irradiation in whole polyps and middle pieces as assessed by q-PCR. (A) Significant up-regulation of HMMP and HMP2 was observed in whole polyps and middle pieces with UV treatment. In whole polyps, treatment with UV at $500 \mathrm{JJ}$ $m^{2}$ resulted in up-regulation of HMP2 from $0.5 \mathrm{~h}$ and continued till $24 \mathrm{~h}$, whereas HMMP showed significant up-regulation from $6 \mathrm{~h}$ post $\mathrm{UV}$ treatment. (B) Middle pieces when irradiated with UV and allowed to recover in hydra medium for 0.5, 24 and 48 h showed significant up-regulation of HMP2 and HMMP at $48 \mathrm{~h}$. Data are represented as mean of three biological replicates with SD. $X$ axis shows different time points and $Y$ axis shows fold change obtained after normalizing $C_{T}$ values against Hyactin. ${ }^{*}$ Statistically significant $(p<0.01) ;{ }^{*}$ statistically significant $(p<0.001)$.

Fig. 5 (Right). Effect of UV irradiation on Wnt signaling in whole polyps as assessed by q-PCR. (A) Significant up-regulation of Wnt and $\beta$-catenin along with Wnt pathway inhibitors, DKK3 and GSK3 $\beta$ was observed. (B) Data from (A) was used to show the trend for Wnt3, DKK3 and GSK3 $\beta$. Data are represented as mean of three biological replicates with SD. X axis shows different time points and $Y$ axis shows fold change obtained after normalizing $C_{T}$ values against Hyactin. ${ }^{* *}$ statistically significant $(p<0.001) ;{ }^{*}$ statistically significant $(p<0.01)$.

Induction of duplicated foot by UV is observed only in a third of the irradiated middle pieces. It is worth considering the possible reasons behind this, especially in view of increased expression of metalloproteinases in whole hydra (present study), where no ectopic foot is induced. Two possibilities may be considered. One concerns localization of the organizing centres in hydra. The two organizing centres are localized at the two extremities of the hydra polyp and one would expect that their molecular influences would be significantly reduced in the middle pieces (that lack them), making reprogramming of patterning possible. The other possibility is that UV irradiation affects fate of some of the multipotent stem cells, the interstitial cells of hydra, which are mostly localized in the body column and are absent from the extremities.

The mechanisms of foot formation in hydra are poorly understood. While a large number of studies on head formation have led to a better understanding of the process, not much is known about specification and formation of foot. A better understanding of the same would lead to crucial information on evolution of axial polarity in metazoans. The present study provides an experimental framework to probe the mechanisms of foot formation in hydra further.

\section{Materials and Methods}

\section{Maintenance of culture}

Clonal culture of Hydra vulgaris Ind-Pune (Reddy et al., 2011) was maintained in hydra medium (Sugiyama and Fujisava, 1977) at $18^{\circ} \mathrm{C}$ with 12 hour day and night cycle. Hydra polyps were fed on alternate days with Artemia salina nauplii and the medium was changed four to five hours after feeding.

\section{Exposure of polyps and middle pieces to UV radiation and foot specific staining}

Hydra were trisected and the middle pieces were irradiated with 500 $\mathrm{J} / \mathrm{m}^{2} \mathrm{UV}$ at $254 \mathrm{~nm}$. These were allowed to regenerate for 4-5 days. Head regeneration was assessed by presence of hypostome and tentacle buds. Visual criteria are not sufficient to detect foot regeneration. Therefore, foot specific staining was performed in control and UV irradiated middle pieces 


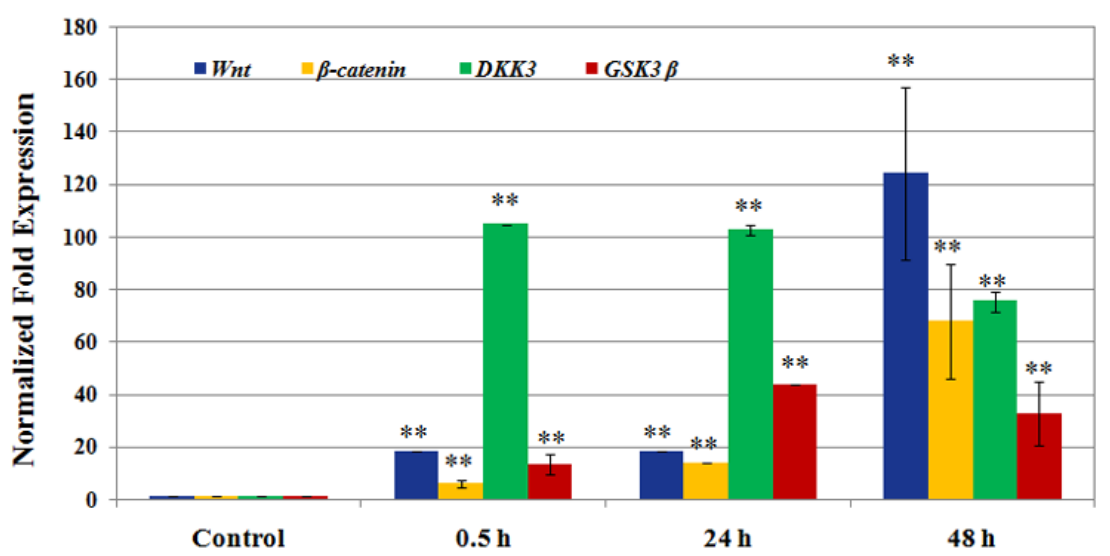

Fig. 6. Modulation ofWnt signaling by UV irradiation in middle pieces of hydra. Up-regulation of DKK3 and GSK3 $\beta$ along with Wnt3 and $\beta$-catenin in UV irradiated middle pieces suggests overall inactivation of Wnt pathway. Data are represented as mean of three biological replicates with $S D$. $Y$ axis shows fold change obtained by normalizing $C_{T}$ values against Hyactin and $X$ axis shows different time intervals. ${ }^{*}$ Statistically significant $(p<0.001)$. as described earlier (Hoffmeister and Schaller, 1985) with few modifications. Briefly, regenerating middle pieces were incubated in $3 \mathrm{ml}$ of freshly prepared staining solution containing citric acid $(65.5 \mathrm{mM})$, trisodium citrate (34.5 mM), 2,2-azino-di (3-ethyl-benzthiazoline-sulfonic acid-6) ammonium salt (ABTS, Sigma, U.S.A) (0.1\%) and hydrogen peroxide (0.003\%) for 5-10 $\mathrm{min}$ at room temperature. The reaction was terminated by transferring the tissue to $1 X$ PBS followed by imaging using SZX16 Stereo microscope (Olympus U.S.A).

For studies on gene expression, $48 \mathrm{~h}$ starved whole hydra polyps or middle pieces of trisected hydra were irradiated with UVC at $254 \mathrm{~nm}$ at $500 \mathrm{~J} / \mathrm{m}^{2}$. After UV irradiation, whole polyps were allowed to grow in hydra medium for various durations, such as, $0.5,1,2,6$ and $24 \mathrm{~h}$ and the middle pieces were harvested after $0.5,6,24$ and $48 \mathrm{~h}$ post UV irradiation. 45 to 50 hydra polyps or about 60 middle pieces of trisected hydra were used for a given time point for RNA extraction, while 10-15 hydra polyps or middle pieces of trisected hydra were used for in situ hybridization for a given time point.

\section{RNA extraction and cDNA synthesis}

Control and UV treated hydra polyps were homogenised in $1 \mathrm{ml}$ of Tri Reagent for total RNA extraction (Chomczynski, 1993). After homogenization, chloroform $(200 \mu \mathrm{l})$ was added to the homogenate, mixed well and centrifuged at $13000 \mathrm{rpm}$ for $15 \mathrm{~min}$ at $4^{\circ} \mathrm{C}$. RNA was precipitated from the aqueous phase using $500 \mu \mathrm{l}$ of isopropanol at $-20^{\circ} \mathrm{C}$ for $30 \mathrm{~min}$. RNA pellet recovered after centrifugation was washed with $70 \%$ ethanol, air-dried, and dissolved in nuclease-free water. RNA was quantified using Nanodrop spectrophotometer and the integrity was checked on $1 \%$ formaldehyde agarose gel. Genomic DNA contamination was eliminated using RQ1

TABLE 1

\section{PRIMER SEQUENCES USED FOR QUANTITATIVE REAL-TIME PCR}

\begin{tabular}{ll} 
Gene name & Primer sequence \\
\hline ActinFW & CAATTGAACACGGAATTGTA \\
ActinREV & AGTAAGAAGGACAGGGTGTTC \\
HMMPFW & GGTTGCAGTTCACGAGATAG \\
HMMPREV & CATCAGACAGCTGAATATTTCTTAC \\
HMP2FW & ACTGATTTGTGTGGGTTTACT \\
HMP2REV & CAGTTCCTCTAGAAGGTGTTTC \\
Wnt3FW & AACAGCCAGCAGAGAAAG \\
Wnt3REV & CAACGACAGTGGACAGATT \\
BetacateninFW & TCAGGCTTCTATTATGGTCAAC \\
BetacateninREV & GCAGTCACACCAACCAAT \\
DKK3FW & GTGTAAGAGAACCAGCCATAAA \\
DKK3REV & ACTTGAGCTCCAACGTAAAC \\
GSK3FW & TTGTTACTAGGCCAACCTATTT \\
GSK3REV & TCATTTCACGAATCTGTTCTCT \\
\hline
\end{tabular}

RNase free DNase as per manufacturer's instructions (Promega) followed by cDNA synthesis (Verso cDNA synthesis kit) and q-PCR.

\section{Quantitative real-time PCR ( $q-P C R)$}

Analysis of expression of Wnt pathway genes and metalloproteinases was carried out by q-PCR. Primers were designed using IDT RealTime PCR Design Tool (Table 1). Initially, semi-quantitative PCRs were performed using q-PCR primers to obtain a single amplicon. Absence of genomic DNA contamination in the RNA was confirmed by performing PCR using DNase treated RNA as a template. This was followed by q-PCRs for adult as well as middle pieces of hydra. Comparable un-irradiated samples served as controls. PCR was performed in a StepOnePlus ${ }^{\mathrm{TM}}$ System (Applied Biosystems, U.S.A.) using Power SYBR Green Master Mix (Invitrogen, U.S.A.) and primers. The PCR conditions were as follows. Initial denaturation at $95^{\circ} \mathrm{C}$ for $10 \mathrm{~min}$ was followed by 40 cycles of denaturation at $95^{\circ} \mathrm{C}$ for 30 $\mathrm{s}$, annealing at $60^{\circ} \mathrm{C}$ for $10 \mathrm{~s}$, denaturation at $95^{\circ} \mathrm{C}$ for $15 \mathrm{~s}$, extension at $60^{\circ} \mathrm{C}$ for $1 \mathrm{~min}$ and final denaturation at $95^{\circ} \mathrm{C}$ for $15 \mathrm{sec}$. Crossover points $\left(\mathrm{C}_{\mathrm{T}}\right)$ were recorded, and quantification was carried out using the standard $2^{-\triangle \Delta C T}$ method. All $C_{T}$ values were corrected by normalizing against the housekeeping gene Hyactin. Data are presented as mean fold change in gene expression relative to untreated control samples. Three biological replicates were carried out and the data are presented as mean $\pm S D$ (standard deviation), and statistical significance was calculated by Student's t test.

\section{Localization of transcripts by in situ hybridization}

Whole mount in situ hybridization using digoxygenin (DIG) labeled riboprobes was carried out as described by Martinez et al., (1997) with a few modifications. Sense and antisense riboprobes were prepared using T7 or SP6 RNA polymerases (Roche). Briefly, hydra polyps and middle pieces were relaxed in $2 \%$ urethane, followed by overnight fixation in $4 \%$ paraformaldehyde at $4^{\circ} \mathrm{C}$. Polyps were permeabilized with proteinase $\mathrm{K}$ and refixed overnight in $4 \%$ paraformaldehyde at $4^{\circ} \mathrm{C}$. Prehybridization was carried out in prehybridization buffer $(50 \%$ formamide, 5 X SSC, $1 \mathrm{X}$ Denhardt's solution, $200 \mathrm{mg} / \mathrm{ml}$ tRNA, 0.1\% Tween 20, 0.1\% CHAPS, 100 $\mu \mathrm{g} / \mathrm{ml}$ heparin) to block non-specific hybridization sites. Hybridization with DIG labeled probes was carried out for $\sim 60 \mathrm{~h}$ followed by washes with hybridization solution and SSC. Polyps were washed in maleic acid buffer with Tween 20 (100 mM maleic acid, $150 \mathrm{mM} \mathrm{NaCl}$ and $0.1 \%$ Tween 20). This was followed by incubation in anti DIG-alkaline phosphatase conjugate antibody (1:3000) overnight at $4^{\circ} \mathrm{C}$. Color reaction was detected by alkaline phosphatase staining with nitroblue tetrazolium (NBT) and 5-bromo-4-chloro3-indolyl-phosphate p-toluidine salt (BCIP) system.

\section{Acknowledgements}

We thank Dr. Vidya Patwardhan, members of the two laboratories and Dr. P. C. Reddy, IISER, Pune for discussions and help. KLS is a Science and Engineering Research Board (SERB) Young Scientist with a Grant 
from Department of Science and Technology, Government of India. AB was recipient of Junior and Senior Research Fellowships (NET) from Council of Scientific and Industrial Research, New Delhi. Saroj Ghaskadbi wishes to thank UGC-Centre of Advanced Studies (UGC-CAS) and DST-PURSE facilities at Department of Zoology, Savitribai Phule Pune University. This work was funded by grants to Surendra Ghaskadbi from SERB, Department of Science and Technology, Government of India and Centre of Excellence in Epigenetics, Department of Biotechnology, Government of India.

\section{References}

AMANO S (2009). Possible involvement of basement membrane damage in skin photoaging. J Invest Dermatol Symp P 14: 2-7.

AUFSCHNAITER R, ZAMIR EA, LITTLE CD, ÖZBEK S, MÜNDER S, DAVID CN, LI $L$, SARRAS MP JR, ZHANG X (2011). In vivo imaging of basement membrane movement: ECM patterning shapes Hydra polyps. J Cell Sci. 124: 4027-4038.

AUGUSTIN R, FRANKE A, KHALTURIN K, KIKO R, SIEBERT S, HEMMRICH G, BOSCH TC (2006). Dickkopf related genes are components of the positional value gradient in Hydra. Dev Biol 296: 62-70.

BARVE A, GHASKADBI S, GHASKADBI S (2013). Conservation of the nucleotide excision repair pathway: characterization of hydra Xeroderma Pigmentosum group F homolog. PLoS One 8: e61062.

BIRKEDAL-HANSEN H, MOORE WGI, BODDEN MK, WINSOR LJ, BIRKEDALHANSEN B, DECARLO A, ENGLER JA (1993). Matrix metalloproteinases: A Review. Crit Rev Oral Biol Med 4: 197-250.

BODE H (2009). Axial patterning in Hydra. Cold Spring Harb Perspect Biol1: a000463. BODE H (2003). Head regeneration in hydra. Dev Dyn 226: 225-236.

BRENNAN M, BHATTIH, NERUSUK, NARASIMHARAOBHAGAVATHULAN, KANG S, FISHER G, VARANI J, VOORHEES J (2003). Matrix Metalloproteinase-1 is the Major Collagenolytic Enzyme Responsible for Collagen Damage in UV-irradiated Human Skin. Photochem Photobiol 78: 43-48.

BRENNEISEN P, SIES H, SCHARFFETTER-KOCHANEK K (2002). Ultraviolet-B irradiation and matrix metalloproteinases: from induction via signaling to initial events. Ann N Y Acad Sci 973: 31-43.

BROUN M, GEE L, REINHARDTB, BODE H (2005). Formation of the head organizer in hydra involves the canonical Wnt pathway. Development 132: 2907-2916.

CHANDLERHL, KUSEWITTDF, COLITZCMH(2008). Modulation of matrix metalloproteinases by ultraviolet radiation in the canine cornea. Vet Ophthalmol 11: 135-144.

CHOMCZYNSKI P (1993). A reagent for the single-step simultaneous isolation of RNA, DNA and proteins from cell and tissue samples. BioTechniques 15: 532-537.

DONG KK, DAMAGHI N, PICART SD, MARKOVA NG, OBAYASHI K, OKANO Y, MASAKI H, GRETHER-BECK S, KRUTMANN J, SMILES KA, YAROSH DB (2008). UV-induced DNA damage initiates release of MMP-1 in human skin. Exp Dermatol 17: 1037-1044.

EASTMAN Q, GROSSCHEDL R (1999). Regulation of LEF/TCF transcription factors by Wnt and other signals. Curr Opin in Cell Biol 11: 233-240.

FEDDERS H, AUGUSTIN R, BOSCH TC (2004). A Dickkopf- 3-related gene is expressed in differentiating nematocytes in the basal metazoan Hydra. Dev Genes Evol 214: 72-80.

FEDI P, BAFICO A, NIETO SORIAA, BURGESS WH, MIKI T, BOTTARO DP, KRAUS $\mathrm{MH}$, AARONSON SA (1999). Isolation and biochemical characterization of the human Dkk-1 homologue, a novel inhibitor of mammalian Wnt signaling. J Biol Chem. 274: 19465-19472.

GHASKADBI SS, SHETYE L, CHIPLONKAR S, GHASKADBI S (2005). Ultraviolet irradiation initiates ectopic foot formation in regenerating hydra and promotes budding. J Biosci 30: 177-182.

GROTEWOLD L, RÜTHER U (2002). The Wnt antagonist Dickkopf-1 is regulated by Bmp signaling and c-Jun and modulates programmed cell death. EMBO J. 21: 966-975.

GUDER C, PHILIPP I, LENGFELD T, WATANABE H, HOBMAYER B, HOLSTEIN TW (2006). The Wnt code: Cnidarians signal the way. Oncogene 25: 7450-7460.

HOBMAYER B, RENTZSCH F, KUHN K, HAPPEL CM, VON LAUE CC, SNYDER P, ROTHBÄCHER U, HOLSTEIN TW (2000). WNT signalling molecules act in axis formation in the diploblastic metazoan Hydra. Nature 407: 186-189.

HOFFMEISTER S, CHICA S (1985). A new biochemical marker for foot-specific cell differentiation in hydra. Roux's Dev Biol 194: 453-461.

KOMIYA Y, HABAS R (2008). Wnt signal transduction pathways. Organogenesis 4: 68-75.

KOVAČEVIĆ G, ŽELJEZIĆ D, HORVATIN K, KALAFATIĆ M (2007). Morphological features and comet assay of green and brown hydra treated with aluminium. Symbiosis 44: 145-152.

LEONTOVICH A, ZHANG J, SHIMOKAWA K, NAGASE H, SARRAS M P JR (2000). A novel hydra matrix metalloproteinase (HMMP) functions in extracellular matrix degradation, morphogenesis and the maintenance of differentiated cells in the foot process. Development 127: 907-920.

MARTINEZD, DIRKSEN M, BODE P M, JAMRICHM, STEELE RE, BODE HR (1997). Budhead, a fork head/HNF-3 homologue, is expressed during axis formation and head specification in Hydra. Dev Biol 192: 523-536.

MOLENAAR M, DESTREE O (1999). A tight control over Wnt action. Int J Dev Biol 43: $675-680$.

MÜNDER S, KÄSBAUER T, PREXL A, AUFSCHNAITER R, ZHANG X, TOWB P, BÖTTGER A (2010). Notch signalling defines critical boundary during budding in Hydra. Dev Biol 344: 331-345.

PAGE-MCCAW A, EWALD A J, WERB Z (2007). Matrix metalloproteinases and the regulation of tissue remodelling. Nat Reviews 8: 221-233.

REDDY PC, BARVE A, GHASKADBI S (2011). Description and phylogenetic characterization of common hydra from India. Curr Sci 101: 736-738.

SALINAS P (2006). Modulation of the microtubule cytoskeleton: a role for a divergent canonical Wnt pathway. Trends Cell Biol 17: 333-342.

SAMBROOK J, FITSCH E F, MANIATIS T (1989). Molecular cloning, A Laboratory Manual, Second Edition, Cold Spring Harbor Laboratory Press, Cold Spring Harb New York, U.S.A.

SARRAS MPJR, ZHANG X, HUFF JK, ACCAVITTIMA, ST JOHN PL, ABRAHAMSON DR (1993). Extracellular matrix (mesoglea) of Hydra vulgaris III. Formation and function during morphogenesis of hydra cell aggregates. Dev Biol 157: 383-398.

SHOU J, ALI-OSMAN F, MULTANI AS, PATHAK S, FEDI P, SRIVENUGOPAL KS (2002). Human DKK-1, a gene encoding a Wnt antagonist, responds to DNA damage and its overexpression sensitizes brain tumor cells to apoptosis following alkylation damage of DNA. Oncogene 21: 878-889.

SUGIYAMA T, FUJISAWA T (1977). Genetic analysis of developmental mechanisms in hydra I. Sexual reproduction of Hydra magnipapillata and isolation of mutants. Dev Growth Differ. 19: 187-200.

YAN L, FEI K, ZHANG J, DEXTER S, SARRAS MP JR (2000). Identification and characterization of hydra metalloproteinase 2(HMP2): a meprin-like astacin metalloproteinase that functions in foot morphogenesis. Development 127: 129-141.

ZHANG X, SARRAS MP, JR (1994). Cell-extracellular matrix interactions under in vivo conditions during interstitial cell migration in Hydra vulgaris. Development 120: 425-432. 


\section{Further Related Reading, published previously in the Int. J. Dev. Biol.}

Eph receptors and ephrin class $B$ ligands are expressed at tissue boundaries in Hydra vulgaris Susanne Tischer, Mona Reineck, Johannes Söding, Sandra Münder and Angelika Böttger Int. J. Dev. Biol. (2013) 57: 759-765

http://dx.doi.org/10.1387/ijdb.130158ab

Identification and characterization of VEGF and FGF from Hydra

Lakshmi-Surekha Krishnapati and Surendra Ghaskadbi

Int. J. Dev. Biol. (2013) 57: 897-906

http://dx.doi.org/10.1387/ijdb.130077sg

How to use Hydra as a model system to teach biology in the classroom

Patricia Bossert and Brigitte Galliot

Int. J. Dev. Biol. (2012) 56: 637-652

http://dx.doi.org/10.1387/ijdb.123523pb

Modeling pattern formation in hydra: a route to understanding essential steps in development

Hans Meinhardt

Int. J. Dev. Biol. (2012) 56: 447-462

http://dx.doi.org/10.1387/ijdb.113483hm

Hydra, a model system to trace the emergence of boundaries in developing eumetazoans Angelika Böttger and Monika Hassel

Int. J. Dev. Biol. (2012) 56: 583-591

http://dx.doi.org/10.1387/ijdb.113454ab

5 yr ISI Impact Factor $(2013)=2.879$
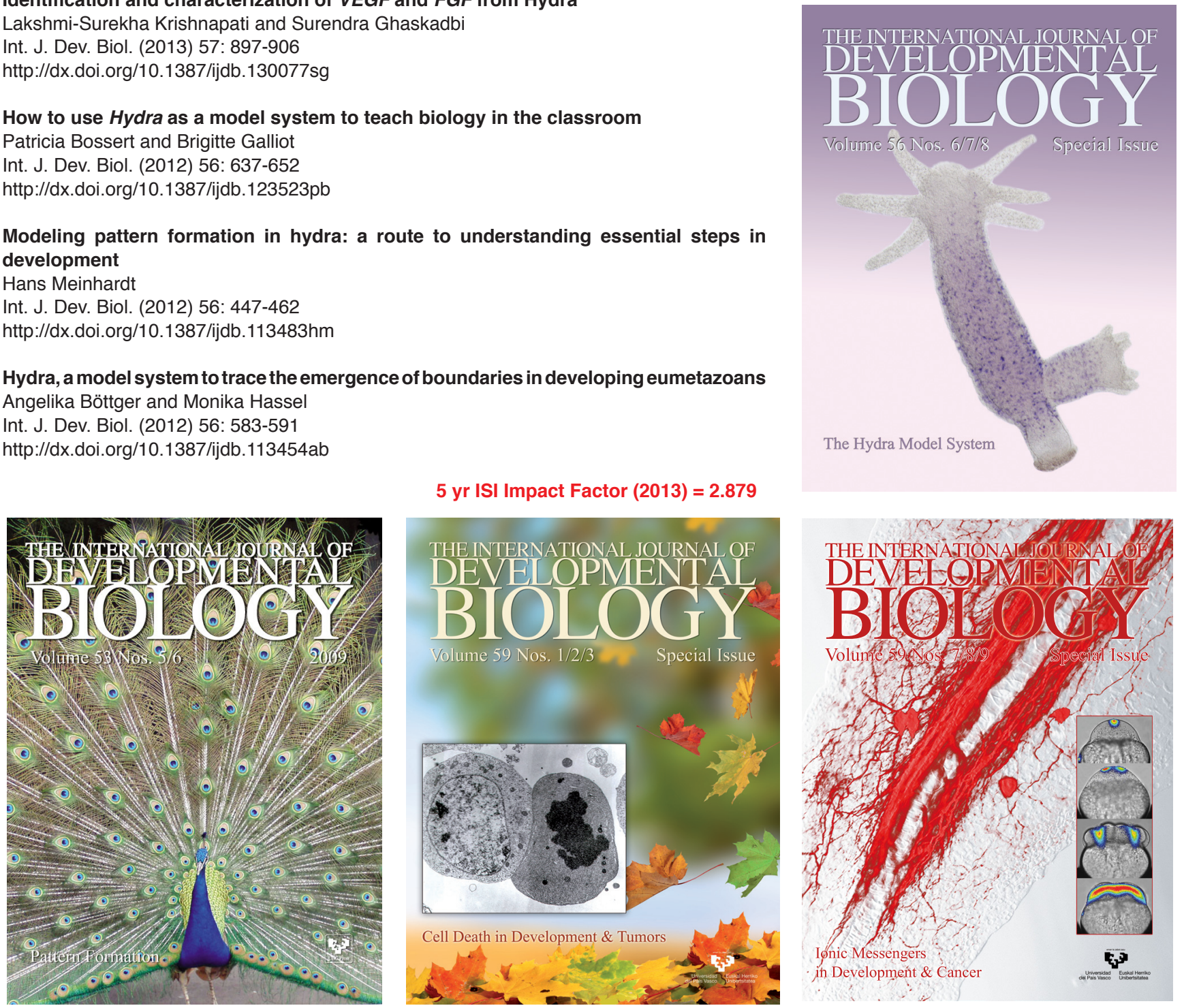